\title{
SECURITIZAÇÃO PODE MELHORAR O ACESSO AO CRÉDITO AGRÍCOLA NO BRASIL?
}

\author{
João Alberto De Negri' \\ Ludmilla Lorrany ${ }^{2}$
}

\section{SINOPSE}

As mudanças tecnológicas nos serviços financeiros e de crédito, em especial as transformaçóes de seus mecanismos e atuais processos de securitização da produção agrícola, podem melhorar o acesso ao crédito agrícola no Brasil? Para dar uma resposta a esta pergunta, este texto busca mensurar a sensibilidade do produtor agrícola às mudanças nas taxas de juros diante da disponibilidade de seguro agrícola das suas operaçóes de crédito no sistema bancário brasileiro.

Palavras-chave: seguro de crédito; securitização; produção agropecuária; crédito rural.

DOI: http://dx.doi.org/10.38116/radar63art5

\section{INTRODUÇÃO}

As mudanças tecnológicas nos serviços financeiros e de crédito, em especial as transformaçóes de seus mecanismos e atuais processos de securitização da produção agrícola, podem melhorar o acesso ao crédito agrícola no Brasil? Para dar uma resposta a esta pergunta, este texto busca mensurar a sensibilidade do produtor agrícola às mudanças nas taxas de juros diante da disponibilidade de seguro agrícola das suas operaçóes de crédito no sistema bancário brasileiro.

\section{O SEGURO DE CRÉDITO AGRÍCOLA}

O princípio da securitização é uma transferência equitativa de um risco de perda em troca de um prêmio ou uma pequena perda quantificável para evitar uma grande perda. O seguro agrícola é uma linha especial de seguro porque há condições específicas para alcançar uma adequada diversificação da natureza dos riscos. Além disso, os custos operacionais e administrativos da prestação de seguros agrícolas podem ser mais altos em comparação com outros tipos de seguro.

A produção agropecuária enfrenta riscos diferenciados dos outros setores econômicos, de maneira que os instrumentos financeiros e de seguro devem levar em conta essas especificidades. Há dois riscos característicos da produção agropecuária que são especialmente correlacionados e sempre estarão presentes. O primeiro é o risco da volatilidade dos preços e o segundo é a incerteza sobre os níveis de produção que os produtores primários podem alcançar com as tecnologias disponíveis. A tendência é que os riscos associados à volatilidade dos preços e aos níveis

1. Técnico de planejamento e pesquisa e coordenador de estudos em financiamento e investimento na Diretoria de Estudos e Políticas Setoriais de Inovação e Infraestrutura (Diset) do Ipea.

2. Pesquisadora do Programa de Pesquisa para o Desenvolvimento Nacional (PNPD) na Diset/lpea. 
de produção aumentem no futuro, em especial por conta da liberalização do comércio e dos efeitos das mudanças climáticas sobre esses níveis produção. Mudanças tecnológicas estão fortemente focadas nestes grandes desafios.

Para apoiar o setor agropecuário, a maioria dos países adota políticas de crédito e seguros. Neste setor, o compartilhamento de informações é também crítico. No Brasil, as políticas públicas têm dado preferência a instrumentos de apoio financeiro, em especial o crédito direcionado. Políticas de garantia de preços e formação de estoques públicos também foram historicamente consolidadas.

Essas políticas têm impacto sobre a produtividade rural, mas não são livres de custos. Os subsídios ao crédito têm custos ficais diretos e também acabam por estreitar os canais de transmissão da política monetária do Banco Central do Brasil (BCB) aos níveis gerais de preços da economia. O Sistema Nacional de Crédito Rural (SNCR) foi criado pela Lei no 4.829/1965 com o objetivo de modernizaçáo da agropecuária nacional, visando financiar atividades de espectro relativamente amplo do setor rural. ${ }^{3}$ Araújo e $\mathrm{Li}^{4}$ construíram um fluxograma do crédito rural no Brasil a partir da Matriz de Dados do Crédito Rural (MDCR). ${ }^{5}$

Novas tecnologias de monitoramento por satélite foram desenvolvidas no período recente para melhorar o monitoramento e reduzir esses custos. A análise de imagem e o uso de inteligência artificial ainda náo conseguem dar conta de toda a complexidade das incertezas da produçáo agropecuária. Maiores custos, assimetrias de informação e características específicas da produção agrícola, como dispersão locacional e fatores climáticos, desafiam as companhias de seguros a serem inovadoras em suas abordagens para o design de produtos e sistemas de distribuiçãa dos serviços.

\section{METODOLOGIA E RESULTADOS}

O modelo econométrico utilizado neste trabalho estima a sensibilidade do produtor agrícola às mudanças nas taxas de juros, nos prazos e no seguro contratado, por meio do volume da carteira ativa de empréstimos ao produtor. Ou seja, podemos considerar que temos uma medida de demanda por crédito sendo explicada por variáveis ligadas à oferta de crédito.

Foram analisados 96 milhóes de contratos de crédito rural provenientes do SNCR do BCB. ${ }^{6} \mathrm{O}$ valor total da carteira ativa para a amostra no período 2004-2018 foi de R \$ 2,9 trilhóes - deflacionados pelo Índice Nacional de Preços ao Consumidor Amplo (IPCA) com base em janeiro de 2017. Os dados na tabela 1 detalham informaçóes adicionais. Neste período, 76,29\% eram recursos direcionados, ou seja, crédito concedido pelo governo com taxas e prazos controlados. A maior parte das operaçôes de crédito possuía garantia, 84,14\%, mas apenas 1,09\% tinha seguro como garantia. $\mathrm{Na}$ amostra selecionada, $89,94 \%$ das operaçóes foram classificadas como crédito rural.

3. Para mais informações, ver: Araújo, P. F. C. de. Política de crédito rural: reflexões sobre a experiência brasileira. Brasília: Ipea, 2011. (Texto para Discussão, n. 1555).

4. Araújo, B. C.; Li, D. L. Crédito rural. In: De Negri, J. A.; Araújo, B. C.; Bacelette, R. Financiamento do desenvolvimento no Brasil. Brasília: Ipea, 2018.

5. Disponível em: <https://www.bcb.gov.br/conteudo/mdcr/Documents/definicoesCreditoRural.pdf>.

6. Ver documento 3040 do BCB, disponível em: <https://www.bcb.gov.br/content/estabilidadefinanceira/Leiaute_de_documentos/scrdoc3040/SCR3040_Leiaute.xls>. 
TABELA 1

Carteira ativa das operações de crédito (2004-2018)

\begin{tabular}{|c|c|c|c|c|c|}
\hline \multicolumn{4}{|c|}{ Características da operação de crédito } & \multirow{2}{*}{$\begin{array}{c}\text { Total }(\mathrm{R} \$)^{1} \\
5.080 .135 .127,90\end{array}$} & \multirow{2}{*}{$\begin{array}{c}\text { Total (\%) } \\
0,17\end{array}$} \\
\hline Sem seguro & Sem garantia & Direcionado & Não rural & & \\
\hline Sem seguro & Com garantia & Direcionado & Não rural & $53.225 .815 .159,74$ & 1,78 \\
\hline Sem seguro & Sem garantia & Direcionado & Rural & $310.870 .049 .321,21$ & 10,39 \\
\hline Sem seguro & Com garantia & Direcionado & Rural & $1.899 .695 .865 .902,00$ & 63,46 \\
\hline Sem seguro & Sem garantia & Livre & Não rural & 18.856.978.657,95 & 0,63 \\
\hline Sem seguro & Com garantia & Livre & Não rural & 206.933.167.050,94 & 6,91 \\
\hline Com seguro & Com garantia & Livre & Não rural & $16.305 .064 .803,02$ & 0,54 \\
\hline Sem seguro & Sem garantia & Livre & Rural & 139.727.122.067,49 & 4,67 \\
\hline
\end{tabular}

Elaboração dos autores.

Nota: ${ }^{1}$ IPCA $=$ janeiro/2017 $=100$.

As menores taxas de juros são contratadas no mercado de crédito direcionado. A taxa de juros no mercado de crédito rural direcionado com garantia e sem seguros foi de $6,48 \%$ ao ano (a.a.) em média no período. Este é o principal mercado de crédito rural, com $63,46 \%$ do valor das operaçóes. A taxa de juros para operaçóes com seguros foi de $6,43 \%$, o que indica pouca variação nas taxas de juros no mercado direcionado para operaçóes com ou sem seguro. As taxas de juros no mercado livre de crédito rural são substancialmente maiores. As operaçóes com garantias foram contratadas com taxas de juros de 50,85\% a.a. e representam 10,90\% do valor total da carteira ativa contratada de crédito para o agronegócio.

As estimativas de elasticidade-juros e prazo da demanda de crédito agrícola com e sem seguro foram feitas para as operaçóes de crédito realizadas com taxas de juros livres. Essas operaçôes são provenientes de: i) poupança rural de aplicação livre, sem porção predefinida por lei; e ii) recursos livres propriamente ditos, ou seja, recursos próprios de bancos comerciais sem porção predefinida por lei. A Letra de Crédito do Agronegócio (LCA) também é fonte de recursos obrigatória e, neste caso, há a exigibilidade de dedicação de uma porção de 35\% para aplicação em operaçóes de crédito rural. Esta obrigatoriedade implica alguma restrição à livre flutuação das taxas de juros no mercado livre de crédito. Há também, no caso da LCA, a disposição de recursos livres, de livre aplicação.

Os resultados indicam que os tomadores de empréstimos rurais no Brasil são mais sensíveis às mudanças nas taxas de juros no mercado de crédito livre quando disponibilizam seguros como garantia. Para operaçóes de crédito rural em geral, a elasticidade-juros da demanda de crédito é de -0,590. Nas operaçóes em que os tomadores não dispóem de seguro para dar como garantia, a elasticidade da taxa de juros da demanda aumenta para -0,632. Para crédito de custeio no mercado livre, a elasticidade-juros da demanda de crédito é de -0,924. Para as operaçóes que dispóem de seguro para dar como garantia, a elasticidade é de -1,057. A elasticidade-juros da demanda de crédito rural para investimento foi de $-0,319$ e praticamente insensível à disponibilidade de seguro por parte do tomador de empréstimo. Os exercícios de média simples mostram que as taxas de juros não são menores nas operaçóes com crédito agrícola com seguro como garantia no Brasil.

Conclui-se que há espaço para a melhoria da política de securitização do mercado de crédito agrícola, em especial no que se refere a açóes de fortalecimento do uso de tecnologias de informação e comunicação para a gestão de riscos na agropecuária. 


\section{CONCLUSÃO}

Os resultados indicam que os tomadores de empréstimos rurais no Brasil são mais sensíveis às mudanças nas taxas de juros no mercado de crédito livre quando disponibilizam seguros como garantia. Nas operaçóes em que os tomadores dispóem de seguro para dar como garantia, a elasticidade da taxa de juros da demanda aumenta. A elasticidade-juros da demanda de crédito rural para investimento, por sua vez, é praticamente insensível à disponibilidade de seguro por parte do tomador de empréstimo. As taxas de juros não são menores nas operaçóes com crédito agrícola que têm seguro como garantia no Brasil.

Açôes de fortalecimento do uso de tecnologias de informação e comunicação são necessárias para a gestão de riscos na agropecuária, como é o caso do Zoneamento Agrícola de Risco Climático (ZARC). Seu aprimoramento depende de incorporar cada vez mais informaçóes dos produtores e compatibilizar estas informaçóes com aquelas do SCR.

O trabalho indica também que a governança dos programas de proteção a riscos agropecuários pode ser mais integrada, tendo em vista que hoje há pelo menos quatro instâncias governamentais gerindo esses programas. $\mathrm{O}$ aumento da concorrência entre agentes seguradores é também importante para impulsionar o mercado e para a melhoria no aprendizado, dada principalmente a necessidade de estimular a diversificação das modalidades de seguros oferecidos. Criar incentivos à cultura de gestão de riscos agropecuários depende da integração entre os instrumentos de crédito, seguro e assistência técnica rural e, especialmente, do uso de novas tecnologias, como a inteligência artificial.

\section{BIBLIOGRAFIA COMPLEMENTAR}

BRASIL. Banco Central do Brasil. Manual do Crédito Rural (MCR). [s.l.]: BCB, [s.d.]. Disponível em: <http://www3. bcb.gov.br/mcr>. Acesso em: 11 nov. 2019. 